\title{
EVALUATION OF CLEANING EFFICACY AND INSTRUMENTATION TIME OF MANUAL K- FILES AND TWO DIFFERENT ROTARY SYSTEMS (PROTAPER NEXT AND PRO AF ROTARY FILES) IN PULPECTOMY OF PRIMARY MOLARS: AN IN VITRO STUDY
}

\author{
Sarah Lutf Sennain*, Mariem Osama Wassel ${ }^{* *}$ and Basma Gamal Awad ${ }^{* * *}$
}

\begin{abstract}
Objective: To compare the cleaning efficacy and instrumentation time of manual K- files and two rotary files (ProTaper Next and Pro AF Baby Gold files) in pulpectomy of primary molars.

Materials and methods: A total of 72 root canals of 57 extracted primary molars (mandibular and maxillary teeth) were divided into three groups; Group I: Manual K- files (M), Group II: ProTaper Next (PTN), Group III: Pro AF Baby Gold (PAF). An insulin syringe was used to inject India ink into all of the root canals. In all groups, the instrumentation time was measured by a digital chronometer. The remaining traces of ink after instrumentation were evaluated by a stereomicroscope to analyze the cleaning efficacy.

Results: No statistically significant differences were found in cleaning efficacy among or within the 3 files systems in the (coronal, middle, and apical thirds), however, PTN and PAF files showed the best cleaning efficacy at the apical third. K- files had the significantly highest instrumentation time compared to PTN and PAF files.
\end{abstract}

Conclusion: Rotary files can be a fast and efficient alternative in the pulpectomy of deciduous molars.

KEYWORDS: ProTaper Next, Pro AF Baby Gold, deciduous teeth, instrumentation time, cleaning efficacy.

\section{INTRODUCTION}

Preservation of primary teeth until physiological exfoliation contributes to aesthetics, mastication, and phonation. Additionally, it prevents deleterious habits in children and helps the eruption of succeeding permanent teeth into an ideal position. ${ }^{(1,2,3)} \mathrm{Al}-$ though, there is no better space maintainer than the primary teeth, the extraction of pulpally involved

\footnotetext{
* Master's Degree student, Department of Pediatric Dentistry and Dental Public Health, Faculty of Dentistry, Ain Shams University.

** Associate Professor, Department of Pediatric Dentistry and Dental Public Health,Faculty of Dentistry, Ain Shams University. *** Lecturer, Department of Pediatric Dentistry and Dental Public Health, Faculty of Dentistry, Ain Shams University.
} 
primary tooth and placement of space maintainer is an alternative to pulpectomy in some situations. ${ }^{(4)}$

However, saving the tooth in the arch for as long as we can is a primary concern in pediatric dentistry. Accordingly, most pediatric dentists have preferred conducting pulpectomy in primary teeth with irreversible pulpitis or necrosis whenever possible. (2) The fundamental goal of endodontic therapy is the removal of bacteria from the root canals. This can be conducted by chemo-mechanical elimination of vital tissues, residual necrotic material, and infected dentine. Therefore, the elimination of organic debris by cleaning and shaping is the most important part of a successful pulpectomy procedure. ${ }^{(5)}$

The pediatric dentist may face many difficulties when performing root canal therapy in children such as difficult instrumentation of tortuous canals, time consumption as well as some behavior problems. These challenges require advanced to up-to-date techniques. ${ }^{(6)}$

Stainless steel hand files have been used for many years for cleaning and shaping the canals. However, they are time-consuming and can lead to iatrogenic errors (i.e., ledging, zipping, canal transportation, and apical blockage) in curved canals rather than straight canals. Therefore, to overcome the disadvantage of the manual files, rotary $\mathrm{Ni}$-Ti was introduced into dentistry. The rotary system has been proven to be effective in permanent teeth by reducing instrumentation time especially in curved molar root canals. ${ }^{(7)}$

Barr et al., (2000) ${ }^{(8)}$ introduced rotary Ni-Ti files to pediatric endodontics for the first time stating that "the flexibility of these files allows them to preserve the original anatomy of curved canals in primary molars".

The longer length of adult rotary files makes it difficult to use in pediatric patients due to their limited mouth opening. So, some rotary Ni-Ti files were specially manufactured for primary teeth which are designed with a shorter length. Some of these available pediatric rotary files are: Kedo-S (Kedo Dental, India), Pro AF Baby Gold (Kids-e-dental, India), Prime Pedo (Sky International Enterprises, India), DXL-Pro Pedo (Kraft marketing, India). ${ }^{(9)}$

Primary molar root canals are usually presented with multiple anatomic variations, and unfortunately there has been no sufficient data in literature studying the effect of the new design modification of rotary files on these canals during preparation. Accordingly, our present study was designed to compare newly introduced rotary $\mathrm{Ni}-\mathrm{Ti}$ files for primary teeth with ProTaper Next (PTN, Dentsply, Maillefer, Ballaigues, Switzerland) rotary files and Manual K- files (M-files, Dentsply, Maillefer, Ballaigues, Switzerland) in respect to their cleaning efficacy and instrumentation time.

\section{MATERIALS AND METHODS}

A power analysis was designed to have adequate power to apply a 2-sided statistical test of the research hypothesis (null hypothesis) that there is no difference between Ni-Ti files and manual K- files regarding cleaning efficacy and instrumentation time according to the results of Ramazani et al. ${ }^{(10)}$ Assuming an alpha $(\alpha)$ level of $0.05(5 \%)$, a Beta ( $\beta$ ) level of $0.20(20 \%)$ i.e. power $=80 \%$, an effect size $(w)$ of (0.62) for cleaning efficacy and (1.15) for instrumentation time. The predicted sample size (n) was a total of (72) root canals i.e. (24) for each group. $\mathrm{G}^{*}$ Power version 3.1.9.2 was used to calculate sample size.

The research protocol received institutional ethical approval with reference number (FDASURecIE011946).

\section{Teeth selection and grouping}

Seventy-two root canals in fifty-seven extracted primary molars (mandibular and maxillary) were collected from the outpatients' clinic of Pediatric Dentistry Department, Faculty of Dentistry, Ain Shams University with the following inclusion 
criteria $^{(10)}$ : 1. Minimum apical resorption with at least $2 \backslash 3$ of root structure present; 2. Patent root canal; 3. Without any previous pulp therapy. Exclusion criteria were teeth with ${ }^{(10,11)}$ : 1. Root caries; 2. Calcified canals; 3. Extreme root canal curvatures.

Teeth were rinsed under tap water to remove all soft tissue from the root surfaces. They were then stored in distilled water at room temperature until the experimental procedure and not more than three months. ${ }^{(12)}$

Teeth were divided into 3 groups: Group $\mathrm{M}$ ( $\mathrm{n}=$ 24 root canals of primary molars) prepared with Manual K-files (Dentsply, Maillefer, Ballaigues, Switzerland); Group PTN ( $\mathrm{n}=24$ root canals of primary molars) prepared with ProTaper Next rotary files (Dentsply, Maillefer, Ballaigues, Switzerland); and Group PAF ( $\mathrm{n}=24$ root canals of primary molars) prepared with Pro AF Baby Gold files (Kids-e-dental, India).

\section{Preparation of teeth}

Access cavities were prepared for all primary molars using large round bur (801/029) (Intensiv SA, Montagnola , Switzerland) mounted in a highspeed hand piece under copious water irrigation. As the pulp chamber was reached, the roof of the pulp chamber was removed to gain access to the root canals. All the overlying dentine was removed with tapered diamond bur (847/017) (Intensiv SA, Montagnola , Switzerland)to achieve a straight-line access into the root canals. The coronal pulp tissue was then removed with excavators. Each canal was irrigated with saline and working length (WL) was determined using \#10 or \#15 K-files (Dentsply, Maillefer, Ballaigues, Switzerland). The file was inserted into the canal and WL was determined $1 \mathrm{~mm}$ short of the apex. The root canals were then rinsed with normal saline, dried with paper points, and isolated with petroleum gel from the outside surface of the tooth. India ink dye (Hardy Diagnostics,
Arizona, USA) was injected into each canal using an insulin syringe (30 gauge) until it leaked from the foramen. ${ }^{(10,13)}$ The ink dye was re-injected inside the canals to ensure dye penetration throughout the canals. Once more a \#10 K-files was re-inserted into the canals to ensure absence of any bubble formed. The teeth were then stored under wet conditions for 48 hours. ${ }^{(11)}$

\section{Preparation of the Canals}

\section{Group M}

Canal preparations were performed using stainless steel (SS) K-files (Dentsply, Maillefer, Ballaigues, Switzerland). Root canal preparation was achieved by the step-back technique following sequential size enlargement from \#15 $\mathrm{K}$ to \#40 K files by the quarter-turn-pull technique. File \#25 was the master apical file followed by stepping back to \#40 K file. ${ }^{(14,15)}$ The instruments were gently pre-curved to help negotiate the canals. ${ }^{(4)}$

\section{Group PTN}

Canal preparations were performed using ProTaper Next files (Dentsply, Maillefer, Ballaigues, Switzerland). Manual instrumentation with size 15 and $20 \mathrm{~K}$-files was used to prepare root canals at first. ${ }^{(16)}$ Rotary files were then introduced under a rotational speed of $300 \mathrm{rpm}$, and torque of $2.0 \mathrm{Ncm}$ using an endodontic motor (Wireless Endo Motor Apple Dental, Foshan Liangya Dental Equipment Co., China.).

The instrumentation succession was as follows: $\mathrm{X} 1$ (size 17, 4\% taper); X2 (size 25, 6\% taper). $(16,17)$ Both instruments were used to full working length. The files were used in a gentle in-and-out pecking motion combined with circumferential action following the manufacturer's instructions. ${ }^{(18,19)}$ Regular cleaning of the flutes was conducted every 3 in-and-out movements. ${ }^{(19)}$ 


\section{Group PAF:}

Canal preparations were performed using Pro AF Baby Gold files (Kids-e-dental, India). Root canals were prepared initially by manual instrumentation using size 15 and 20 K-files. Rotary files were then introduced under a rotational speed of 300 $\mathrm{rpm}$, and torque of $2.0 \mathrm{Ncm}$ using an endodontic motor (Wireless Endo Motor Apple Dental, Foshan Liangya Dental Equipment Co., China.).

The canals were prepared to the working length with different sizes of files, depending upon the width of the canals according to the manufacturer's instructions. B1 (\#20,17mm, 4\% taper) and B2 (\#25,17mm 4\% taper) for narrow (mesiobuccal, mesiolingual, distobuccal) canals, B2 (\#25, 17mm, 4\% taper) and B3 (\#25,17mm, 6\% taper) for medium (mesiobuccal, mesiolingual, distobuccal) canals, B2 (\#25,17mm, 4\% taper) and B4 (\#30,17mm, 4\% taper) for wide (distal and palatal) canals. The files were used in a gentle in-and-out pecking motion combined with circumferential action.

In all the experimental groups, a size 10 $\mathrm{K}$-file was used to check canal patency after each instrument removal. Furthermore, each canal was irrigated with $5 \mathrm{ml}$ of 1.0 percent sodium hypochlorite solution and $5 \mathrm{ml}$ normal saline using disposable syringes after each root instrumentation and at the completion of instrumentation. After that, each canal was dried using a sterile paper point size 25 . $^{(21)}$ Each file was used to prepare five canals and was then discarded. ${ }^{(22)}$

The cavities were then restored with temporary fillings and apical foramens were sealed with sticky wax. Specimens were stored under wet condition.

\section{Assessment of Instrumentation Time}

In all groups, the total time of active instrumentation, instrument changes, and irrigation, was calculated using a digital chronometer. Five canals were instrumented at once to overcome any bias in preparation that might happen due to operator fatigue. ${ }^{(23)}$

\section{Assessment of cleaning efficacy}

After instrumentation, each tooth was placed separately in a glass jar with a lid containing 7\% hydrochloric acid. ${ }^{(14,24,25)}$ The acid solutions were changed daily in order to maintain their efficacy until the tooth was completely decalcified (for two days), Figure (1a). ${ }^{(15,24)}$ The teeth were then cleansed under running water until all of the acid had been rinsed away from the surface. ${ }^{(10)}$

Teeth were then dehydrated using a series of ethyl alcohol concentrations: first a 70\% alcohol for 16 hours (which was replenished every 8 hours), then an $80 \%$ alcohol for eight hours, followed with 95\% alcohol for eight hours, finally, 100\% alcohol for 8 hours, Figures (1b) and (1c). ${ }^{(9,11,24,26)}$

Teeth were then placed in methyl salicylate until they became transparent in appearance following the decalcification and dehydration process. It took nearly 6 hours for teeth to get completely cleared, Figure (1d). The samples were then kept in the methyl salicylate solution until they were analyzed..$^{(9,26)}$

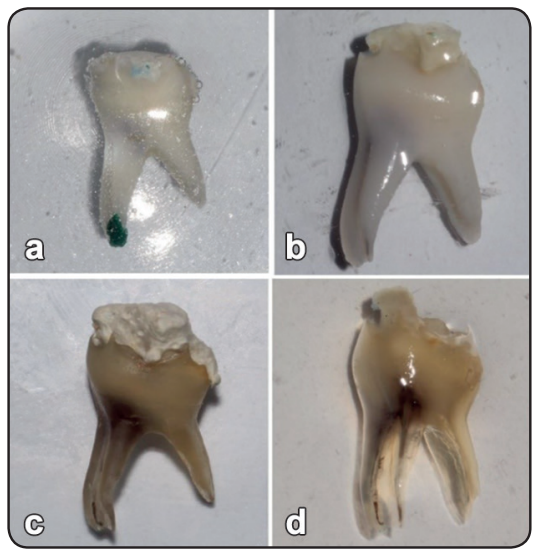

Fig. (1) Preparation of teeth to assess the cleaning efficiency. (a) decalcification in $7 \% \mathrm{HCL}$, (b) dehydration in $70 \%$ Alcohol, (c) after dehydration with $100 \%$ Alcohol, (d) clearing the tooth with methyl salicylate. 


\section{Analysis of the root canals}

Teeth were first sectioned buccolingually, and then were immersed in a glass petri dish with methyl salicylate and carefully examined under a stereomicroscope $(\times 10$ magnification, Olympus, Japan). The India-ink was then inspected by two blind examiners (Kappa score $=0.727$ ) in the cervical, middle, and apical thirds using a 4-points scoring system which evaluates ink removal along the root canal walls as follows ${ }^{(27)}$ Figure (2):

$\mathbf{0}=$ The canal was totally clean .

$\mathbf{1}=$ Almost complete ink removal (more than $50 \%$ ink removal).

$\mathbf{2}=$ Partial ink removal, (less than 50\% ink removal)

$\mathbf{3}=$ No ink removal.
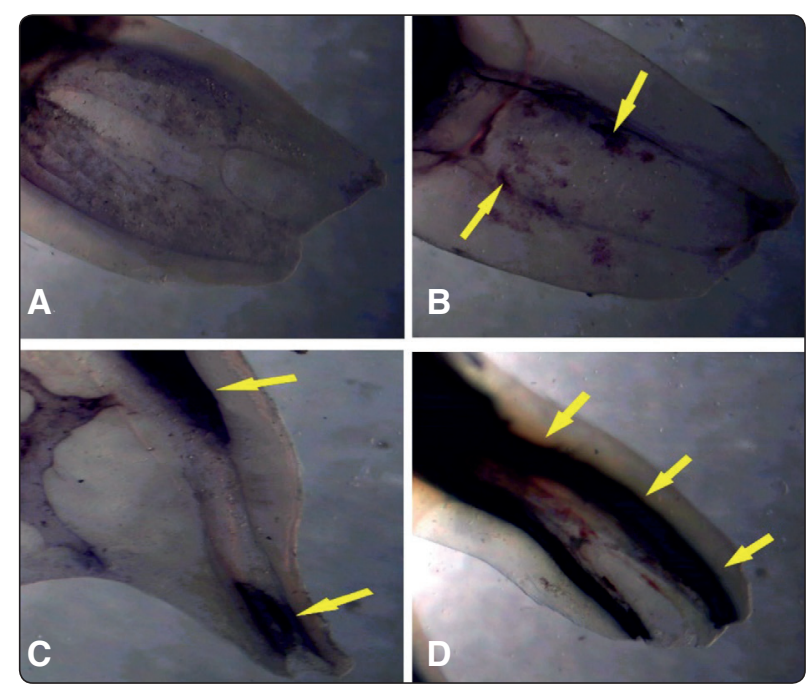

Fig. (2): Grading scores for cleaning efficacy. (A): Score 0 : Total cleaning, in which the whole canal was completely clean. (B) Score 1: Almost complete ink removal (more than 50\% ink removal). (C) Score 2: Partial ink removal (less than $50 \%$ ink removal), note that ink was removed from the middle third only. (D) Score 3: No ink removal. Yellow arrows denote the traces of ink remaining in root canal.
Numerical data were represented by mean and standard deviation (SD) values and were explored for normality by checking the data distribution, calculating the mean and median values, and using Kolmogorov-Smirnov and Shapiro-Wilk tests. Parametric data were analyzed using oneway ANOVA for intergroup comparison. For the non-parametric data intergroup comparisons were analyzed using the Kruskal Wallis test, while intragroup comparisons were analyzed using Freidman's test of repeated measures. The significance level was set at $\mathrm{p} \leq 0.05$ within all tests. Statistical analysis was performed with $\mathrm{IBM}^{\circledR}$ SPSS ${ }^{\circledR}$ Statistics Version 26 for Windows.

\section{RESULTS}

\section{Cleaning Efficacy}

Results of Kruskal Wallis and Freidman's tests showed that there were no statistical significant differences in cleaning efficacy in any of the 3 horizontal planes either within each group or among the 3 groups. However, PTN and PAF files showed the lowest scores (better cleaning) in both the coronal and apical thirds (Table 1).

TABLE (1): Mean \pm standard deviation (SD) of cleaning score for different groups

\begin{tabular}{|c|c|c|c|c|}
\hline \multirow{2}{*}{ Section } & \multicolumn{3}{|c|}{ Cleaning score $(\mathrm{mean} \pm \mathrm{SD})$} & \multirow{2}{*}{ p-value } \\
\cline { 2 - 5 } & Group-M & Group-PTN & Group-PAF & \\
\hline Coronal & $0.71 \pm 0.62^{\mathrm{Aa}}$ & $0.38 \pm 0.49^{\mathrm{Aa}}$ & $0.54 \pm 0.51^{\mathrm{Aa}}$ & $0.150 \mathrm{~ns}$ \\
\hline Middle & $0.50 \pm 0.51^{\mathrm{Aa}}$ & $0.38 \pm 0.49^{\mathrm{Aa}}$ & $0.58 \pm 0.72^{\mathrm{Aa}}$ & $0.600 \mathrm{~ns}$ \\
\hline Apical & $0.62 \pm 0.49^{\mathrm{Aa}}$ & $0.54 \pm 0.59^{\mathrm{Aa}}$ & $0.50 \pm 0.66^{\mathrm{Aa}}$ & $0.564 \mathrm{~ns}$ \\
\hline p-value & $0.156 \mathrm{~ns}$ & $0.234 \mathrm{~ns}$ & $0.735 \mathrm{~ns}$ & \\
\hline
\end{tabular}

Different upper and lowercase superscript letters indicate a statistically significant difference within the same horizontal row and vertical column respectively*; significant $(p \leq 0.05) n s ;$ non-significant $(p>0.05)$

\footnotetext{
${ }^{\circledR}$ IBM Corporation, NY, USA.

${ }^{\circledR}$ SPSS, Inc., an IBM Company.
} 


\section{Instrumentation time}

Results of the one-way ANOVA test showed that there was a statistical significant difference between different groups $(\mathrm{p}<0.001)$. The highest instrumentation time was found in the $M$ group (05:48 $\pm 01: 56)$ followed by PTN (03:37 $\pm 00: 52)$, while the lowest value was found in the PAF group (03:05 $\pm 00: 54)$. Post hoc pairwise comparisons showed M- group to have a significantly higher value than other groups $(\mathrm{p}<0.001)($ Table 2$)$.

TABLE (2): Mean \pm standard deviation (SD) of instrumentation time (mm:ss) for different groups

\begin{tabular}{|c|c|c|c|}
\hline \multicolumn{2}{|c|}{ Instrumentation time (mm:ss) } & \multirow{2}{*}{ p-value $\pm \mathrm{SD})$} \\
\cline { 1 - 2 } Group-M & Group-PTN & Group-PAF & \\
\hline $05: 48 \pm 01: 56^{\mathrm{A}}$ & $03: 37 \pm 00: 52^{\mathrm{B}}$ & $03: 05 \pm 00: 54^{\mathrm{B}}$ & $<0.001^{*}$ \\
\hline
\end{tabular}

Different superscript letters indicate a statistically significant difference within the same horizontal row*; significant $(p \leq 0.05) n s ;$ non-significant $(p>0.05)$

\section{DISCUSSION}

Root canal treatment is a complex procedure comprising removal of the pulp tissue, residual necrotic materials, debris, and infected dentine. (28) The anatomy of primary tooth pulp comprise a greater number of accessory canals, lateral canals, fins, anastomoses between canals and an apical delta, short and thin roots, so it considered more complicated than the anatomy of permanent teeth. ${ }^{(22,29)}$ Moreover, behavioral management of children makes pulpectomy of primary teeth more difficult. ${ }^{(10)}$

It has always been a challenge to pediatric dentists the process of completion of root canal therapy in the shortest time possible whilst providing a good quality treatment through the efficient removal of infected tissues as well as achieving a proper seal for the canals by a biocompatible material. ${ }^{(5)}$
In this study, the cleaning efficacy and instrumentation time of manual K- files and two rotary file systems (ProTaper Next and Pro AF Baby Gold) in primary molars were evaluated as to the current date no study was performed regarding the evaluation of these three systems together, especially that the Pro AF Baby Gold was specially designed to be used in primary teeth, so it was important to evaluate its performance and compare it to other products already available in the market.

In regards to the cleaning efficacy, results showed no statistical significant difference among different groups and values at different sections within each group. As per the coronal part, it was found that the mean score was lowest (best cleaning efficacy) in the rotary (PTN) group followed by (PAF) group and the highest mean score was found in the (M) group. This could be due to the greater percentage of taper (4\% and 6\%) of Pro AF Baby Gold files and ProTaper Next, respectively, in comparison to manual K- files (2\%). The bigger the diameter of rotary files, the more it contacts the surrounding dentine and thus provides better cutting efficiency. On the other hand, the stiffer the cross-section of the file used as in the K-files, the more pressure they can apply on the surrounding dentinal walls resulting in higher debridement.

This finding was similar to Mehlawat et al. ${ }^{(30)}$, Madan et al. ${ }^{(31)}$, and Silva et al. ${ }^{(32)}$ results. However, our findings came in contrast to the results of Moghaddam et al. ${ }^{(33)}$ where the cleaning efficacy of the hand files group was noted to be better than the rotary files group. The authors stated that this could be related to the operators' tendency to place hand instruments further coronally. ${ }^{(33)}$

As per the cleaning efficacy in the middle third of roots, it was shown that the (PTN) group had the lowest mean score followed by (M) and (PAF) groups, however, the difference was not statistical significant. In line with our results, Ramazani et al. ${ }^{(10)}$, found that there was no statistically significant 
difference in cleaning efficacy in the middle third between rotary and manual $\mathrm{K}$ - files. In contrast to ours, Mehlawat et al. ${ }^{(30)}$ found that manual K- files showed greater effectiveness in cleaning the root canal in the middle third. This might be explained by the fact that rotary files have an increased taper thus they exert minimal pressure in the middle third while engaging more dentine at the coronal part of the canal. This can result in the lower debridement noted at the middle third.

When cleaning efficacy in the apical thirds of root canals was compared, the lowest mean value was found in the (PAF) group, followed by the (PTN) group, and the highest mean value was found in the $(\mathrm{M})$ group, though the difference was not significant. This correlates with Moghaddam et al. ${ }^{(33)}$ and Ramazani et al. ${ }^{(10)}$ studies who found no differences in cleaning efficacy in the apical and middle thirds of cleaning efficacy between rotary flex files and hand files. In addition, some studies reported that complete apical third cleaning is hard to be achieved by either rotary or manual instrumentations. ${ }^{(24,34)}$

Roa et al. ${ }^{(11)}$ found that PTN showed better cleaning efficacy than ProTaper Universal and K- files. In our study PTN and PAF groups were better in cleaning efficacy than manual $\mathrm{K}$ - files in the apical one-third. This could be as a result of the apical taper of the PTN X2 file (6\%) and the apical taper of Pro AF baby Gold B2 and B4(4\%) which might be the reason for the superior cleaning efficacy of rotary files than manual files in the apical third of root canal.

As per the instrumentation time, the result showed a statistical significant difference between different groups $(\mathrm{p}<0.001)$. In addition, post hoc pairwise comparisons showed that the $(\mathrm{M})$ group had a significantly higher value than the other rotary groups. Despite that, no difference was found between (PTN) and (PAF) groups, while the lowest value was found in (PAF) group (03:05 $\pm 00: 54)$.
The time necessary for root canal preparation was the subject of many investigations. ${ }^{(9,14,15,35,36,37)}$ In accordance with our study, some previous studies found that the use of a rotary instrument in primary teeth results in a marked reduction in the instrumentation time. ${ }^{(37,38,39)}$ Rao et al. (11) in agreement with our study indicated a shorter instrumentation time with PTN compared with manual K- files.

Moreover, Panchal et al. (40) compared the obturation quality and instrumentation time after root canal instrumentation with rotary (pediatric files) Kedo-S files, hand $\mathrm{K}$-files, and $\mathrm{H}$-files in primary molars. Their result showed that Kedo-S files had the least instrumentation time compared to the other two groups. These results came in accordance with our study where the rotary files especially the Pro AF Baby Gold files had the shortest instrumentation time in comparison to the manual K-files.

The shorter time required with the rotary instrumentation is probably related to the reduced number of instruments ${ }^{(41)}$ and greater efficacy of dentine cutting. ${ }^{(42)}$ In addition, rotary instrumentation reduces the need for manual dexterity, thereby increasing the efficiency of the operator and reduces hand fatigue. ${ }^{(43)}$

Many authors reported that one of the advantages of rotary files in primary teeth is decreasing the working time that aids in maintaining patient cooperation by shortening the chair time which also, in turn, diminishes the potential for operator tiredness. ${ }^{(44,45)}$

In contrast to our study, one study showed an increase in instrumentation time with the use of ProFiles, whereas it took less time with K-files. However, this was attributed to the operator's experience. ${ }^{(31)}$

Similarly, Katge et al. (26) found that manual instrumentation using $\mathrm{H}$-files took less time than rotary instrumentation with (Mtwo files). This came 
also in contrast to our study. The reason for lesser instrumentation time was attributed to the time wasted in the process of exchange of rotary files and as a matter of operator's experience. ${ }^{(26,31)}$

In our study, $6 \mathrm{~K}$-files were used (\#15-\#40) to prepare each canal of the manual group, while in rotary groups only 4 files were used per canal. In addition, $\mathrm{K}$ - files were pre-curved before inserting in the canal, while the rotary files were not. This could be another reason for increasing the instrumentation time in the manual $\mathrm{K}$ - file group.

\section{CONCLUSION}

Within the limitations of the present study, it can be concluded that:

1. The cleaning ability of the three files was similar, however, none showed complete canal cleaning.

2. PTN and PAF rotary files showed the best apical cleaning efficacy, however, there was no significant difference compared to hand K-files.

3. Instrumentation time was significantly less with rotary files as compared to hand $\mathrm{K}$ - files. Pro AF Baby Gold showed the shortest working time, probably due to the fewer number of used files in this system. This could result in decreased chair side time thereby positively influencing the child's behavior.

\section{ACKNOWLEDGEMENT}

We would like to express our gratitude to Dr. Mohamed Mokhtar Nagy, Associate professor, Endodontic department, Faculty of Dentistry, Ain Shams University for his support.

\section{REFERENCE}

1. Thakkar TK, Naik S, Ghule K. Advances in Rotary Endodontics in Pediatric Dentistry. Review Article. EC Dent Sci. 2019;5(18):1320-1330.

2. Thakur B, Hospital SHN, Pawar AM, Kfir A, Neelakantan P. Extrusion of Debris from Primary Molar Root Canals following Instrumentation with Traditional and New File Systems. J Contemp Dent Pract. 2017;18(11):1040-1044.

3. Johnson MS, Britto LR, Guelmann M. Impact of a biological barrier in pulpectomies of primary molars. Pediatr Dent. 2006;28(6):506-510.

4. Hargreaves KM, Berman LH, Waterhouse PJ, et al. COHEN'S PATHWAYS of the PULP. Vol 11th ed. 11th ed. Elsevier; 2016;213-248.

5. Nerkar R, Yadav S, Mehta V, Joshi P. Root canal preparation in primary teeth with nickel-titanium rotary files: A Review. J Adv Oral Res. 2015;6(2):1-4.

6. Juliet S, Jeevanandan G, Govindaraju L, Ravindran V, Subramanian E. Comparison between Three Rotary Files on Quality of Obturation and Instrumentation Time in Primary Teeth-A Double Blinded Randomized Controlled Trial. J Orofac Sci. 2020;12(1):30-34.

7. Dua P, Saini S, Mangla R, Chauhan A. Rotary Endodontics in Pediatric Dentistry: Embracing the New Alternative. Int J Clin Pediatr Dent. 2019;12(5):460-463.

8. Barr ES, Kleier DMDDJ, Barr DMDN V. Use of nickeltitanium rotary files for root canal preparation in primary teeth. Pediatr Dent. 2000;22(1):77-78.

9. Katge F, Ghadge S, Poojari M, Jain K, Patil D. Comparative Evaluation of Cleaning Efficacy of Prime Pedo TM and DXL-Pro TM Pedo Rotary Files with Conventional H Files in Root Canals of Primary Teeth : An In Vitro Study. J Clin Diagnostic Res. 2019;13(7):6-9.

10. Ramazani N, Mohammadi A, Amirabadi F, Ramazani M, Ehsani F. In vitro investigation of the cleaning efficacy, shaping ability, preparation time and file deformation of continuous rotary, reciprocating rotary and manual instrumentations in primary molars. J Dent Res Dent Clin Dent Prospects. 2016;10(1):49-56.

11. Rao A, Pandya D, Roy S, Upadhyay K, Gupta S, Pal A. Comparison of instrumentation time and cleaning efficacy of manual K-file, rotary ProTaper Universal and rotary ProTaper Next in primary anterior teeth: An in-vitro study. 2018;7(1):27-30.

12. Ozcan G, Sekerci AE, Cantekin K, Aydinbelge M, Dogan $\mathrm{S}$. Evaluation of root canal morphology of human primary molars by using CBCT and comprehensive review of the literature. Acta Odontol Scand. 2016;74(4):250-258.

13. Gavini G, dos Santos M, Caldeira CL. Nickel-titanium instruments in endodontics: A concise review of the state of the art. Braz Oral Res. 2018;32:44-65. 
14. Walsch H. The hybrid concept of nickel-titanium rotary instrumentation. Dent Clin North Am. 2004;48(1):183202.

15. Kuzekanani M. Nickel-Titanium Rotary Instruments: Development of the Single-File Systems. J Int Soc Prev Community Dent. 2018;8(5):386-390.

16. Türker SA, Uzunoğlu E. Apical root canal transportation of different pathfinding systems and their effects on shaping ability of protaper next. J Clin Exp Dent. 2015; 7(3): e392-e395.

17. Tavanafar S, Gilani PV, Saleh A. Shaping ability of ProTaper Universal, ProTaper NEXT and WaveOne Primary in severely curved resin blocks. J Contemp Dent Pract. 2019;20(3):363-369.

18. Manker A, Solanki M, Tripathi A, Jain ML. Biomechanical preparation in primary molars using manual and three NiTi instruments: a cone-beam-computed tomographic in vitro study. Eur Arch Paediatr Dent. 2019;21(2):203-213.

19. Al Rwaily AKJ. Rotary Systems Versus Manual K-File System in Primary Molar Root Canals -In Vitro Study. Interv Pediatr Dent Open Access J. 2018;2(2):115-120.

20. Chandler N, Chellappa D. Lubrication during root canal treatment. Aust Endod J. 2019;45(1):106-110.

21. Poornima P, Disha P, Nagaveni NB, Roopa KB, Bharath $\mathrm{KP}$, Neena IE. "Volumetric analysis of hand and rotary root canal instrumentation and filling in primary teeth using Spiral Computed Tomography" - an invitro study. Int J Paediatr Dent. 2016;26(3):193-198.

22. Shaikh SM, Goswami M. Evaluation of the Effect of Different Root Canal Preparation Techniques in Primary Teeth Using CBCT. J Clin Pediatr Dent. 2018;42(4):250-255.

23. Musale PK, Mujawar SAV. Evaluation of the efficacy of rotary vs. hand files in root canal preparation of primary teeth in vitro using CBCT. Eur Arch Paediatr Dent. 2014;15(2):113-120.

24. Katge F, Patil D, Pimpale J, Poojari M, Shitoot A, Rusawat B. Comparison of instrumentation time and cleaning efficacy of manual instrumentation, rotary systems and reciprocating systems in primary teeth: An in vitro study. J Indian Soc Pedod Prev Dent. 2014;32(4):311-316.

25. Ramezanali F, Afkhami F, Soleimani A, Kharrazifard MJ, Rafiee F. Comparison of cleaning efficacy and instrumentation time in primary molars: Mtwo rotary instruments vs. Hand K-files. Iran Endod J. 2015;10(4):240-243.
26. Katge F, Chimata VK, Poojari M, Shetty S, Rusawat B. Comparison of cleaning Efficacy and Instrumentation Time between Rotary and Manual Instrumentation Techniques in Primary Teeth: An in vitro Study. Int J Clin Pediatr Dent. 2016;9(2):124-127.

27. Pinheiro SL, Neves LS, Imparato JCP. Analysis of the instrumentation time and cleaning between manual and rotary techniques in deciduous molars. RSBO. 2012;9(3):238-244.

28. Jeevanandan G, Govindaraju L. Clinical comparison of Kedo-S paediatric rotary files vs manual instrumentation for root canal preparation in primary molars: a double blinded randomised clinical trial. Eur Arch Paediatr Dent. 2018;19(4):273-278.

29. Sharma P, Kurthukoti AJ, Swamy DF, Shashidara R, Swamy EB. Computed Tomographic Morphometry of the Internal Anatomy of Mandibular Second Primary Molars. Int J Clin Pediatr Dent. 2015;8(3):202-207.

30. Mehlawat R, Kapoor R, Gandhi K, Kumar D, Malhotra $\mathrm{R}$, Ahuja S. Comparative evaluation of instrumentation timing and cleaning efficacy in extracted primary molars using manual and NiTi rotary technique - Invitro study. J Oral Biol Craniofacial Res. 2019;9(2):151-155.

31. Madan N, Rathnam A, Shigli A, Indushekar K. K-file vs ProFiles in cleaning capacity and instrumentation time in primary molar root canals: An in vitro study. J Indian Soc Pedod Prev Dent. 2011;29(1):2-6.

32. Azar MR, Safi L, Nikaein A. Comparison of the cleaning capacity of Mtwo and Pro Taper rotary systems and manual instruments in primary teeth. Dent Res J( Isfahan). 2012;9(2):146-151.

33. Moghaddam KN, Mehran M, Zadeh HF. Root Canal Cleaning Efficacy of Rotary and Hand Files Instrumentation in Primary Molars. Iran Endod J. 2009;4(2):1-5.

34. Azar MR, Mokhtare M. Rotary Mtwo system versus manual K-file instruments: Efficacy in preparing primary and permanent molar root canals. Indian J Dent Res. 2011;22(2):363.

35. Hulsmann M, Peters OA, Dummer PMH. Mechanical preparation of root canals: shaping goals, techniques and means. Endod Top. 2005;10(1):30-76.

36. Jeevanandan G, Thomas E. Volumetric analysis of hand, reciprocating and rotary instrumentation techniques in primary molars using spiral computed tomography: An in vitro comparative study. Eur J Dent. 2018;12(1):21-26. 
37. Ochoa-Romero T, Mendez-Gonzalez V, Flores-Reyes H. Comparison Between Rotary and Manual Techniques on Duration of Instrumentation and Obturation Times in Primary Teeth. J Clin Pediatr Dent. 2011;35(4):359-364.

38. Govindaraju1 L, Ganesh Jeevanandan1 EMGS. Comparison of quality of obturation and instrumentation time using hand files and two rotary file systems in primary molars: A single-blinded randomized controlled trial. Eur J Dent. 2017;11(4):192-195.

39. Singh N. Comparison of hand K-files and NiTi rotary files in Biomechanical Preparation Of Root Canals. J Adv Med Dent Scie Res. 2018;6(7):129-133.

40. Panchal V, Jeevanandan G, Subramanian EMG. Comparison of instrumentation time and obturation quality between hand K-file, H-files, and rotary Kedo-S in root canal treatment of primary teeth: A randomized controlled trial. J Indian Soc Pedod Prev Dent. 2019;37(1):75-79.
41. Baugh D, Wallace J. The role of apical instrumentation in root canal treatment: A review of the literature. J Endod. 2005;31(5):333-340.

42. Bahrololoomi Z, Tabrizizadeh M, Salmani L. In vitro comparison of instrumentation time and cleaning capacity between rotary and manual preparation techniques in primary anterior teeth. Front Dent. Published online 2007:59-62.

43. George S, Anandaraj S, Issac JS, John SA, Harris A. Rotary endodontics in primary teeth - A review. Saudi Dent J. 2016;28(1):12-17.

44. Crespo S, Cortes O, Garcia C, and Perez L. "Comparison between rotary and manual instrumentation in primary teeth.” J Clin Pediatr Dent. 2008;32(4):295-298.

45. Ozen B, Akgun OM. A comparison of Ni-Ti rotary and hand files instrumentation in primary molars. J Int Dent Med Res. 2013;6(1):6-8. 